EPOS, XIII (1997), págs. 77-88

\title{
LOS DEVANEOS DE ERATO: EL MUNDO CLÁSICO DE ANA ROSSETTI
}

Eugenio Ramón LuJÁn MaRTínez

Universidad Complutense de Madrid

\section{RESUMEN}

Como ejemplo del uso de temas y motivos del mundo clásico grecolatino en la poesía española de este final de siglo, se analiza en este artículo el importante papel que éstos desempeñan dentro del universo poético de Ana Rossetti. Entre otras características, se pueden señalar la frecuente contaminación con motivos cristianos hacia los que es posible la transición por medio de un elemento común y, en general, el gusto por el choque cultural que se produce por la mezcla de aquéllos con referencias a otras épocas y culturas.

La constante influencia del mundo clásico en la tradición poética española es innegable y en los últimos tiempos estamos asistiendo a un notable desarrollo de los estudios encaminados a ponerla de relieve. Resulta entonces lícito preguntarse si dicha influencia sigue siendo perceptible ( $\mathrm{y}$ de qué manera) en la poesía de estos últimos años del siglo. Por ello nos ha parecido interesante realizar un estudio de detalle del papel del mundo clásico en el universo poético de una de las más reconocidas poetisas actuales, Ana Rossetti. Para una contextualización de nuestro estudio remitimos al prólogo de Luis 
Antonio de Villena a su antología Fin de siglo ${ }^{1}$, en el que ha trazado las líneas generales de la presencia de la «tradición clásica» en la poesía española desde los novísimos hasta la generación del 80 , aunque con la advertencia de que el concepto de «tradición clásica» es utilizado por Villena en un sentido más amplio del que nosotros hemos tenido en mente a la hora de llevar a cabo este estudio. ${ }^{2}$

La producción poética de Ana Rossetti se abre con el libro Los devaneos de Erato, ${ }^{3}$ publicado en 1979 y que, significativamente, incluye en su título la mención de la musa de la lírica y especialmente de la lírica amorosa, pues ya desde este primer libro se evidencia la vena que vertebrará toda la poesía de la primera etapa de Ana Rossetti: su acendrado erotismo. Ese título permite adivinar también el frecuente recurso al mundo clásico como fuente de motivos, temas e imágenes del que se valdrá como recurso poético esta autora.

El libro comienza con el poema «Paris», en el que el mítico personaje y su belleza se convierten precisamente en símbolos de ese erotismo. Se inaugura así lo que será la presentación habitual que ofrezca en su obra de los personajes masculinos cuya belleza es uno de los rasgos que de ellos resalta el mito. Y también aparece ya una forma de tratar el mito clásico muy del gusto de la poetisa: dotarlo de nuevas connotaciones por medio de la contaminación con elementos de la tradición cristiana hacia los que es posible la transición gracias a la presencia de un objeto común a ambos. En este caso será la disputa entre las tres diosas la que adquiera un nuevo sentido cuando la mención de la manzana traiga consigo reminiscencias bíblicas.

Tus piernas, esas cintas que el vello deshilacha y en la ojiva, el pubis, manojo de tu vientre,

la dovela.

Crece en tu torno el gladiolo,

llave anal, violador perenne,

$y$ tres diosas

quieren morder contigo la manzana.

1 De Villena, L. A., ed. (1992): Fin de siglo. Antología, Madrid, Visor, pp. 9-34.

2 «Con lo que (aunque prensado) no me parece inexacto decir que la tradición clásica (lírica) es (aparte de la transmisión de topoi, de citas o referencias directas) un poema elegíaco, experiencial y de fabricación culta, sea en el mismo utillaje retórico, sea en las alusiones mitológicas o librescas. [...] Con lo que un poeta de tradición clásica. terminaría siendo, también, no sólo quien se refiera explícitamente a la grecolatinidad, sino a cualquier otro autor anterior, que no contradiga de manera expresa, la fórmula general citada». (L.A. de Villena, op. cit. p. 11).

${ }^{3}$ Para todos los poemas hasta 1984 seguimos la siguiente edición: RossetT1, A. (1985): Indicios vehementes (Poesía 1979-1984), Madrid, Hiperión. 
Esta mezcla de mitos clásicos y cristianos es aún más profunda en «A Sebastián, virgen», poema en el que las flechas sirven para enlazar la imagen clásica de Eros como arquero y la del mártir San Sebastián asaeteado.

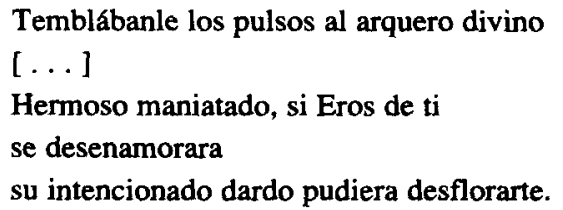

En «Con motivo de un cojín a petit point» se reelabora el mito de Narciso en un barroco juego de intertextualidad: la dedicatoria a Germán Sánchez Espeso remite a la novela emblemática de éste, Narciso, y al -podríamos decir- juego de espejos realidad/ficción sobre el que se articula aquélla, para engarzarse con el motivo de los narcisos que están siendo bordados en el bastidor y, confundiéndose con la imagen del personaje mítico, desembocar al final del poema en una declaración de amor.
Cual narciso bebras de ti mismo
en el espejo, ignorante tú de todo
lo que tú no fueras, y los labios pegabas
a tus labios.
Y me he prendido a ti más que tú mismo.
Violentamente te amo más que tú me amas.

«Diotima a su muy aplicado discípulo» se articula en su título como una responsión a las palabras que Sócrates utiliza en el Banquete $201 \mathrm{~d}$ en el preámbulo a la reproducción de su diálogo con Diotima: $\tau \kappa \alpha \grave{z} \delta \delta[\delta \alpha \xi \xi \varepsilon v$ [«la cual fue además mi maestra en las cuestiones de amor»]. Pero según el Banquete la profetisa, aun utilizando un lenguaje cargado de metáforas femeninas en torno a la preñez, el amor en el que instruyó a Sócrates fue el correcto amor de los muchachos ( $\delta \rho \theta \hat{\omega} \zeta \pi \alpha t \delta \varepsilon \rho \alpha \sigma \tau \varepsilon \hat{i v})^{4}$. En cambio, en el poema de Ana Rosetti Diotima se transforma en maestra del discípulo que con ella misma habrá de ejercitar lo aprendido.

- Para la interpretación del personaje de Diotima, que ha llamado desde siempre la atención de los filologos clásicos por ser precisamente una mujer, vid. ahora el interesante estudio de HALPERIN, D. M. (1990): "Why is Diotima a woman?», One Hundred Years of Homosexuality and Other Essays on Greek Love, Nueva York-Londres, Routledge, pp. 113-151. 


\begin{abstract}
Apresúrate, ven, recibe estos pétalos
de rosas, pétalos como muslos

de impolutas vestales, velados. Que mi boca

rebose en sus sedosos trozos, tersos y densos

cual labios asomados a mis dientes

exigiendo el mordisco. Amordázate,

el jadeo de tu alto puñal, y sea tu beso

heraldo de las flores.
\end{abstract}

Por otra parte, el poema resulta también muy significativo en cuanto a los usos poéticos habituales en la poesía española desde los novísimos por lo que toca al modo de utilizar los motivos clásicos: su entreveramiento con elementos culturales completamente anacrónicos con ellos. El choque de épocas se puede percibir en este caso ya desde la cita que sigue inmediatamente al título: «El placer es el mejor de los cumplidos.» (Cocó Chanel) Y se continúa después en la utilización de un léxico que sólo deja la esencia de la Diotima concebida por la poetisa, pero no su entorno cultural: otomanas, faldas y la mesita del té que aparecen en el poema configuran un ambiente claramente no griego en el que ha de reinterpretarse la alusión clásica.

También se verá reelaborado en este poemario el mito de la Gorgona, de la que, depurada de sus connotaciones negativas, sólo quedará en «Murmullos en la habitación de al lado» el hechizo asombroso de su mirada, asimilada a la de la amante, y las serpientes enroscadas como metáfora de los cabellos ensortijados.

\footnotetext{
Mi mano introduzco

hasta tu nuca, cual víboras

se enroscan rizos en mis dedos.

Duérmete sobre el liso vientre, Gorgona seductora, lejos de mis estupefactos ojos apoyo tu mejilla. [...] Te lo ruego, las persuasivas flores de tus párpados, ciérralas, duerme sobre mi liso vientre.
}

En Los devaneos de Erato tiene un papel fundamental la memoria, que traerá el recuerdo de los años de la adolescencia (« ¿tengo yo la culpa de que las musas sean hijas de Mnemosine?», dirá Ana Rossetti en la entrevista con Jesús Fernández Palacios que sirve de prólogo a Indicios vehe- 
mentes $^{5}$ ), en los que Eros se presiente y se desea al tiempo que se teme. Las flores se convierten en metáforas de ese presentimiento y se mezclan con las alusiones clásicas en poemas como «El gladiolo blanco de mi primera comunión se vuelve púrpura», en el que esa flor aparece al servicio de $\mathrm{Hi}$ meneo.
Desconfío del tumescente
gladiolo blanco, satinadas pastas
de misales antiguos.
[........]
Y sin embargo, qué hermoso señuelo, jamás halló Himeneo instructor más propicio.
Ya visita, de noche, silente, las alcobas, se introduce en los sueños
y despierta a las virgenes con dura sacudida.

En «Cibeles ante la ofrenda anual de tulipanes», poema imbuido del ambiente orgiástico que caracterizaba las celebraciones en honor de esta diosa, será el tulipán la flor que aparezca con esas connotaciones. Recordemos los versos de Ovidio, Fastos IV 345-346:
ipsa sedens plaustro porta est inuecta Capena:
sparguntur iunctae flore recente boues
[ «Sentada en su carro pasa por la puerta Capena:
una lluvia de flores frescas cae sobre la yunta de vacas»].

Para citar a continuación los de Ana Rossetti:
Alta flor tuya erguida en los oscuros parques;
oh, lacérame tú, vulnerada derribame
con la boca repleta de tu húmeda seda.

También Perséfone aparecerá en este poemario, en la parte III de «Anónimos que no tuve más remedio que olvidar en la furgoneta de un pianista», pero en un contexto del todo diferente, como mera evocación en una sucesión de bellas metáforas de la música que insisten una y otra vez sobre la idea de blancura. Recordemos ${ }^{6}$ que en las Cerialia, celebradas, según se deduce de Ovidio

3 Publicada originalmente en Fin de siglo, revista de literatura (Jerez de la Frontera), 6-7, 1983.

- Agradezco al prof. J. M." Lucas que llamara mi atención sobre este punto. 
Amores III 10.45, para conmemorar el regreso de Perséfone sobre la tierra, eran blancos los vestidos que llevaban las mujeres romanas, como el propio Ovidio nos ha transmitido en sus Fastos IV 619-620: alba decent Cererem; vestis Cerialibus albas/ sumite [ $\ll \mathrm{El}$ color blanco es apropiado para Ceres; poneos vestidos blancos para las fiestas Ceriales»].

Tu música, un mantel de incansables gaviotas.

Borbotones de cal, hirientes claridades

y el quitón de Perséfone, de pronto almidonado, anunciando el levante en las salinas.

$Y$ en la parte $V$ de "Anónimos...», cuando el poema desemboca en el tumulto del amor, será con Afrodita desnuda surgiendo de las aguas con la que se identificará la poetisa.

La blanca Anadiomena de septiembre, desnuda de sus túnicas rosadas, crepita, luminosa, bajo el sol.

Desechadas cortezas numerosas, por tus hábiles manos desprovista de cotidianos velos, rotas máscaras, me entrego a los furores de mi sangre.

Paradojicamente -en principio-, teniendo en cuenta el exaltado erotismo del poemario, éste se cierra con un «Triunfo de Ártemis sobre Volupta», en el que el mito del baño de la diosa virgen que a nadie es permitido contemplar se reelabora -recuérdese lo dicho a propósito de «Diotima a su muy aplicado discípulom - de la siguiente manera:

Tras de los balcones atisbaba ansiosa

y a los suplicantes ojos se negaba

si de vuestros deseos tenía certidumbre.

No os consintió ni una sola hebra de su túnica, ni tan siquiera que hurgarais entre sus collares.

Ni pudisteis, a través de una cerradura, mirar cómo parsimoniosa se desvestía haciendo crecer su desnudo desde la bañera.

Pero el triunfo de Ártemis es tan sólo aparente y está en función de la contraposición entre el erotismo experto ( «Sabéis ya en qué precisos/lugares de mi piel Eros se asienta») y el deseo erótico aún no consumado. 
Bajo el encabezamiento «Otros poemas» aparece en la edición de Indicios vehementes un conjunto de seis poemas que quedaron fuera de Los devaneos de Erato pero pertenecen al mismo ciclo y época. También en ellos se encuentran alusiones y referencias al mundo clásico. Así, hay ecos báquicos en los versos de «Mi jardín de los suplicios» que dicen:

Bailé furiosamente.

Cual halo tras de mí henchíase la túnica, en torno a ti crecían los aros de mis huellas.

Yo, tanagra diversa, evasivo laurel y tú quieto.

El gramático Servio en su vida de Virgilio, haciéndose eco de una tradición documentada también en otras fuentes, nos dice del poeta:

adeo autem uerecundissimus fuit, ut ex moribus cognomen acceperit; nam dictus est Parthenias. omni uita probatus uno tantum morbo laborabat; nam inpatiens libidinis fuit [ $\mathrm{Y} Y$ era tan pudoroso que por su manera de ser recibi6 un apodo: le llamaban la virgencita. Integro en todos los aspectos de su vida, sólo padecía un defecto: era insensible al deseo amoroso.»]

Éste es el Virgilio que, como símbolo del rechazo amoroso, sirve de motivo al poema «Dulce venganza».

Cerrándoseme el libro, navío el pensamiento te hostiga y te persigue, y me devuelve al mar. Al mar que era Virgilio, celeste y esmeralda, - tan extenso el infierno- que Virgilio era Haendel, Virgilio era el deseo que me llevaba a ti; de la noche, desvelo era Virgilio, el errar de los astros, la vigilante esfera del reloj; y el sueño conseguido tan sólo un cruel consuelo. Pero ahora puedo hacer como que tú me amabas, que Orión, elevándose, a ti me conducía -curva de la mañana transparentey el beso era posible como el tierno cimbreo de rojas buganvillas, húmedas todavía por la niebla.

Jenofonte , Anábasis IV 7.21 ss ,, nos ha dejado una vívida narración del momento en que los diez mil llegaron al mar y los hombres creyeron así haber alcanzado el final de su azarosa expedición: 


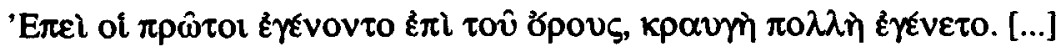

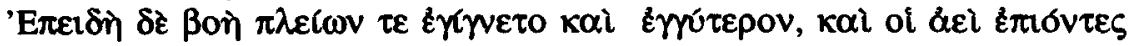

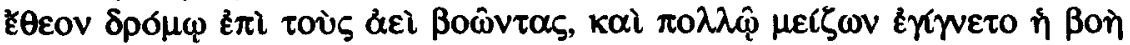

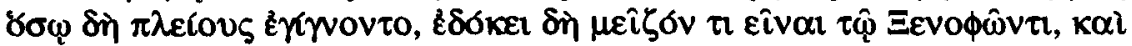

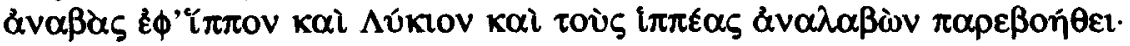

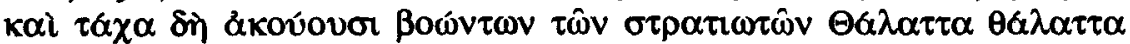

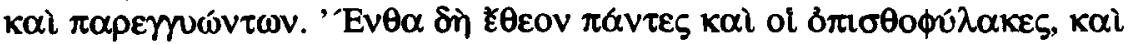

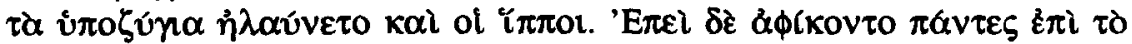

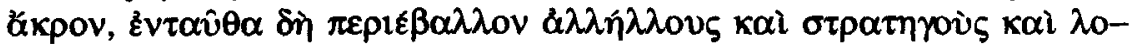

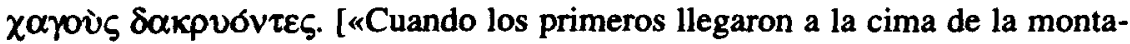
ña se levant 6 un gran estruendo. El griterío crecía cuanto más cerca estaban y los que iban llegando corrían a unirse a los anteriores, que no paraban de gritar, con lo que el griterío aumentaba a medida que había más hombres. Esto hizo creer a Jenofonte que algo grave sucedía, así que se subio al caballo y, llevándose consigo a Licio y a sus jinetes, acudio en su ayuda: en seguida se dan cuenta de que el grito que va de boca en boca de los soldados es «el mar, el mar». Entonces todos, incluso los de la retaguardia, apresuraron la marcha, y también las bestias de carga y los caballos corrían. Y una vez en la cima se abrazaban unos a otros y abrazaban a los generales y a los capitanes llorando.»]

Pues bien, Ana Rossetti ha sabido captar la sensación que desencadenó en esos hombres la contemplación del mar y en el poema «Al mar que avistaron los diez mil» nos hace verlo con los ojos de aquéllos.

$Y$ aún dormido no cede tu hermosura ni hay tregua para el sol que prende sus estrellas sobre tu piel movible, ni cesan las flotantes madejas de las algas de entretejer encajes entre tus piemas prietas. [...]

Muchacho turbador, ya en el recodo último del sendero se avivan tus presagios $y$, aún dormido, te hundirás en los ojos, colgarás tus doseles en las rudas miradas de quienes de servir al feroz Ares vuelven y aún dormido, dulcísimo bribón, y aún dormido, de improviso te muestras y de improviso abres diez mil heridas rojas en las que la luz dora las letras de tu nombre.

También el segundo libro de poemas de Ana Rossetti lleva en su título una referencia mitológica: Dióscuros. Fue publicado en 1982, el mismo año en el 
que apareció otro poemario de idéntico título, obra de Leopoldo María Panero. Pero si el poemario de Panero rebosa referencias clásicas (Dioniso, Cibeles, Atis, Júpiter, Ceres, Plutón ... y el inolvidable verso «Filóstrato, si muero ¿beberás de mis venas?») ni una sola alusión explícita al mundo clásico se encuentra en el de Ana Rossetti. ¿Por qué el título? Es como si Ana Rossetti de alguna manera hubiera querido corregir la tradición antigua que impropiamente llamaba Dioscuros a Cástor y Polideuces cuando de los dos tan solo este último era hijo de Zeus. Quienes eran hijos de Zeus y -si con propiedad se hubiese establecido el nombre- hubieran debido ser llamados Dioscuros, eran Polideuces y Helena. Los diez poemas que integran este libro evocan precisamente una estrecha relación hermano-hermana, Anna y Louis, con tintes incestuosos a veces, a través de la cual la poetisa vuelve de nuevo sus ojos a la infancia y primera adolescencia.

Indicios vehementes, aparecido en 1985, recogió los poemarios anteriores y añadió como dos nuevas partes «Indicios vehementes» $y$ «Sturm und Drang». La única alusión al mundo clásico que aparece en ellas es la referencia a Sófocles que se encuentra en el poema «Se dat suis manibus», en el que el verso tomado del pange lingua sirve como título a un poema dedicado al naufragio que llevó a la muerte a Keats. Sofocles aparece mencionado tan sólo porque era uno de los autores caros a Keats cuyos libros - según Ana Rossetti- le acompañaban en la nave que naufrago.

Esta ruptura con el mundo clásico es consciente, pues la propia poetisa dirá en la entrevista con Jesús Fernández Palacios a la que aludíamos antes: «Lo que está claro es que hay en Los devaneos algo que ya no me funciona estéticamente. Demasiado Apolo Sauróctono. $Y$ todo en esta vida no van a ser curvas praxitélicas habiendo existido un James Dean, por ejemplo.»

Así pues, no es de extrañar que Devocionario ${ }^{7}$, aparecido en 1986, ignore el mundo clásico como motivo, pues en él la imaginería poética la integran martirios, éxtasis místicos, santos devotos... Sin embargo, los temas clásicos reaparecen en Yesterday ${ }^{8}$, publicado en 1988 y organizado en cinco grupos de cinco poemas, de los que los dos primeros constituyen una antología de sus libros anteriores, a la que se añaden quince poemas no recogidos en ellos. Proximo a la estética de Devocionario se encuentra el grupo de las « 5 devociones». En una de ellas, «Turris eburnea» se produce - al estilo de lo que ya hemos visto en poemas anteriores- una contaminación de temas clásicos y cristianos. La advocación mariana «torre de marfil» sirve en este caso para desencadenar en la poetisa el recuerdo de Príapo:

7 RossetTi, A. (1986): Devocionario, Madrid, Visor.

RossetTi, A. (1988): Yesterdary, Madrid, Torremozas. 
El solícito Priapo

de vides revistió el adónico pubis

mutilado, las sonrosadas algas

de la herida.

Entre el grupo de los «5 últimos» se encuentra el que lleva por título «La tua voce come il coro delle sirene di Ulisse m'incatena...», en el que el motivo de la seducción por la voz se elabora por medio del choque cultural tan del gusto de la reciente poesía española entre el ambiente que evoca el título y los objetos que aparecen en el poema, pues la seducción se lleva a cabo en este caso por medio del teléfono.

$\mathrm{Ni}$ los anillos firmes del cable reluciente eran única vía a tu febril mensaje, ni la fiel grabadora de algún contestador su destino final e intransferible.

No.

No era sólo al teléfono a quien tu habilidad de amante convencía, porque yo te escuchaba.

Tras un silencio poético de varios años Ana Rossetti ha vuelto a publicar un poemario en 1995, Punto umbrio ${ }^{9}$, que se abre con una cita de San Agustín: «He hecho de mí un enigma a vuestros ojos. Ésta es mi trágica dolencia.» El tono de su poesía se ha transformado: la pasión y el erotismo exaltado han dejado paso a una serena reflexión sobre el paso del tiempo y la (im)posibilidad de compartir las emociones y el amor. El mundo clásico ya no proporciona brillantes imágenes poéticas, pero el espíritu que alentó algunas de sus producciones de mayor hondura imbuye los poemas de Ana Rossetti, y el nombre de Horacio acude casi sin quererlo al leer poemas como:

NO QUIERAS DE HOY MÁS QUE, DÓCIL, EL DIA cumpla su plazo.

Que vaya, al vivir, siendo.

Lejos de las conjunciones de los horóscopos que no predecirán la belleza ni impedirán su destrucción.

[...]

No, no quieras de hoy más que, enamorado, el dia, al contemplarse,

9 RossetT, A. (1995): Punto umbrio, Madrid, Hiperión. 
se conciba, se nutra y, por sí mismo, muera.

Que en sí se reconozca y se perciba

lejos de las conjuraciones de los astros y de las abjuraciones

de los verbos,

lejos de esta irresistible rebeldía que, sin embargo,

embarga.

Y la $\alpha \pi \delta \theta \varepsilon \imath \alpha$ horaciana -epicúrea o estoica, tanto da- revive bajo el bello nombre de «quietud» en versos que culminan en una nueva formulación del espíritu del quam minimum credula postero que cierra la $O d a$ I 11.

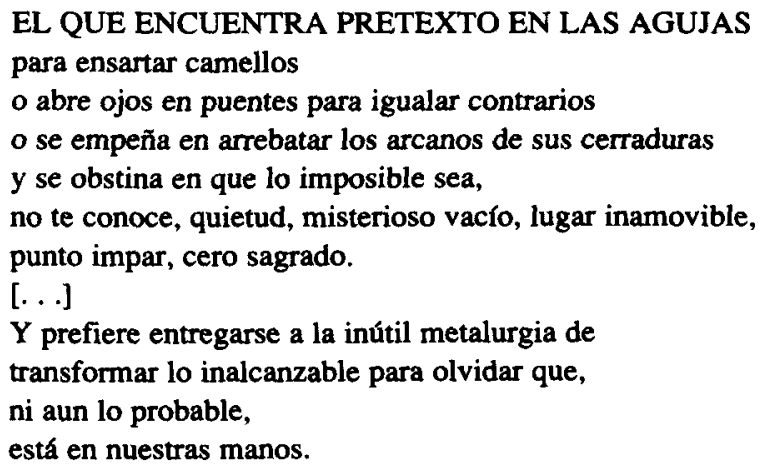

El tema de la muerte como destino universal del hombre está muy presente en la poesía de Horacio ${ }^{10}$, y también una de sus facetas, la imposibilidad de predecir su llegada, que constituye el motivo de los versos finales de la Oda IV 7: quis scit an adiciant hodiernae crastina summae/ tempora di superi ? [ ¿QQuién sabe si los dioses que habitan en lo alto van a añadir el tiempo de manana al total vivido hasta hoy?»] El mismo motivo hallamos en los siguientes versos de Ana Rossetti:

\section{PERO, AHORA, LA LAMPARA VIGILA TODA LA noche, toda la noche, sin saber hasta cuándo debe durar su desazón. \\ Porque se vive con el corazón incomunicado, atisbando cada sombra que cruza, cada pisada, cada vestigio; cualquier mutación se convierte en señal: en la alarma}

${ }_{10}$ Véanse al respecto las magistrales páginas de OTón, E. (1976): «Horacio y su poesía de muerte", Estudios Clásicos 20, pp. 49-71. 
de no reconocer, por la alteración de la sangre, la llegada de la sentencia o de la gracia.

[...]

Porque se vive con el corazón alerta, en espera de su ejecución. Y es del todo imposible domar el río del

tiempo para que fluya o se detenga sin abrir acantilados

bajo nuestros pies.

Y también en los del poema que así comienza:
AMAÑADA O NO LA PARTIDA, TRUCADOS O NO
los dados, se agita el cubilete.
Cuándo se volcará.
Los puntos que decidirán que se ha acabado el juego cuándo se espolvorearán sobre el fieltro de la noche.
Cuándo avanzará el fin estremeciendo las baldosas; asaeteando el laberinto donde están encarcelados los días; estrechando, amenazadoramente, las tinieblas.
Cuándo se alcanzará la aldaba.
Cuándo se destrabarán las cerraduras para que el huracán invada las paredes y lo abierto en el espacio se derroche.
Cuándo se acorralarán, uno por uno, todos los alegatos
y se cercenará cada garfio aferrado a los barrotes como
a una extrema apelacion.
Cuándo se acelerará el balanceo de los relojes hasta apurar las fechas concedidas.

Vemos, pues, - ya que Ana Rossetti es sólo uno de los ejemplos que se podrían aducir- cómo el mundo clásico (sus mitos, sus temas, sus preocupaciones...) sigue vivo en la lírica española actual. Necesariamente las formas de apropiación y los modos de utilización poética han cambiado de acuerdo con la transformación de la poesía española en los últimos decenios. La recepción del mundo clásico _-desde su inmutabilidad de tiempo pasado- no puede escapar a lo que a propósito de la imposibilidad material de que varíe un libro recordaba Pierre Bourdieu ${ }^{11}$ :

Un spécialiste de la Chine, Levenson, disait a peu pres qu'on oublie qu'un livre change par le fait qu'il ne change pas alors que le monde change. C'est tres simple. Quand le livre reste et que le monde tout alutur changes. lo livere change.

1 En el marco de la entrevista entre P. Bourditu y R. Char TIER que sirve de colofón al volumen de Chartier, R., ed. (1985): Pratiques de la lecture, Paris-Marsella, Rivages, p. 236. 